\title{
Anticancer effects of olive oil polyphenols and their combinations with anticancer drugs
}

\author{
JELENA TORIĆ \\ ANA KARKOVIĆ MARKOVIĆ \\ CVIJETA JAKOBUŠIĆ BRALA \\ MONIKA BARBARIĆ* \\ University of Zagreb Faculty \\ of Pharmacy and Biochemistry \\ 10000 Zagreb, Croatia
}

Accepted July 2, 2019

Published online September 9, 2019

\begin{abstract}
Cancer presents one of the leading causes of death in the world. Current treatment includes the administration of one or more anticancer drugs, commonly known as chemotherapy. The biggest issue concerning the chemotherapeutics is their toxicity on normal cells and persisting side effects. One approach to the issue is chemoprevention and the other one is the discovery of more effective drugs or drug combinations, including combinations with polyphenols. Olive oil polyphenols (OOPs), especially hydroxytyrosol (HTyr), tyrosol (Tyr) and their derivatives oleuropein (Ole), oleacein and oleocanthal (Oc) express anticancer activity on different cancer models. Recent studies report that phenolic extract of virgin olive oil may be more effective than the individual phenolic compounds. Also, there is a growing body of evidence about the combined treatment of OOPs with various anticancer drugs, such as cisplatin, tamoxifen, doxorubicin and others. These novel approaches may present an advanced strategy in the prevention and treatment of cancer.
\end{abstract}

Keywords: olive polyphenols, anticancer, chemoprotective, synergism

\section{INTRODUCTION}

Cancer (malignant tumor or neoplasm) develops from normal cells that have the ability to proliferate and grow abnormally. These cells can eventually become malignant and have the potential to metastasize into other tissues and organs. Cancer diseases are growing and causing millions of deaths worldwide, while the cancer therapy presents one of the major medical challenges nowadays with the continuous need for improvement in therapeutic approach (1-3).

The global burden of cancer 2018 database (GLOBOCAN 2018) accessible online as a part of the International Agency for Research on Cancer (IARC) in 185 countries, provides an estimate of the incidence and mortality for 36 types of cancer. It is estimated that this database has grown to 18.1 million new cases and 9.6 million deaths in 2018. One out of five men and one out of six women worldwide develop cancer during their lifetime; one out of

\footnotetext{
*Correspondence; e-mail: mbarbaric@pharma.hr
} 
eight men and one out of eleven women die from cancer diseases. The total number of survivals within the 5 years of the cancer diagnosis, called the 5 -year prevalence, is estimated to be 43.8 million worldwide. The top three cancer types are lung, breast and colorectal cancer in terms of incidence, and they are ranked among the top five in terms of mortality. Taken together, these three types of cancer are responsible for one-third of cancer incident and mortality in the world $(1,4)$.

The most effective approach in the treatment of cancer is surgery combined with chemoand radiotherapy. Unfortunately, tumor cells can become resistant to these therapies, due to the ability of cancer cells to modify drug targets, efflux chemotherapeutic drugs, increase the production of anti-apoptotic proteins and modulate different signal transduction pathways involved in carcinogenesis $(5,6)$. The foremost problem in cancer chemotherapy is the toxicity of chemotherapeutic drugs on normal cells and persisting side effects. The most common side effects are illness, easy bruising or bleeding, hair loss and the other, including nausea and vomiting neuropathy, trouble breathing, constipation and diarrhea (7). Hence, there is an urgent need for the discovery of newer and more effective drugs or drug combinations. An alternative approach is chemoprevention, which consists of using synthetic, semisynthetic or natural agents to inhibit or reverse the process of carcinogenesis, particularly in individuals with a high risk of developing cancer (8).

In the last few years, many plant-derived polyphenols have been subject to numerous studies due to the beneficial effect on human health and the more studied anticancer effect. Some combinations of polyphenols exhibit biological activities different from those detected with individual phenolic compounds (6, 9-12). Moreover, polyphenols interact additively, synergistically or antagonistically with each other, with other food components as well as with drugs $(8,13)$. Synergistic effects can be produced if they affect different targets or improve the solubility of each other and thereby enhance the bioavailability (14).

Several in vitro and in vivo studies have shown that the combination of natural polyphenols with chemotherapeutics can increase the anticancer efficacy, reduce the side effects of chemotherapy and overcome the chemo- or radio-resistance of cancer cells $(6,15,16)$. Some examples of poly phenols potentially capable of sensitizing tumor cells to chemo- and radiotherapy through inhibition of pathways that lead to treatment resistance are genistein, resveratrol, silymarin, caffeic acid phenethyl ester, flavopiridol, emodin, green tea polyphenols, piperine, oleandrin, ursolic acid, and betulinic acid (17-19). The use of natural polyphenols in combined treatment with chemotherapeutics can modulate the anticancer effects of conventional cancer treatment (20-22). In the recent years, the interest in olive oil polyphenols (OOPs) has significantly increased (23-26) initially because of their cardioprotective effect exerted through the Mediterranean diet (MD) (27-29). European Food Safety Authority (EFSA) authorized the health claim that 'olive oil polyphenols contribute to the protection of blood lipids from oxidative stress' (30). These beneficial cardioprotective effects show significantly reduced levels of oxidized low-density lipoprotein (LDL) in plasma after consumption of virgin olive oil. Consequently, with the approval of this health claim, a global increase in the number of studies investigating the potential prevention and improvement of health through OOPs emerged.

Olive oil (OO) phenolic compounds exert a possible chemoprotective and anticancer activities in different types of cancer cells $(23,31-33)$ : breast cancer (BC) $(34,35)$, colon (36), prostate (37), melanoma (38), promyelocytic leukemia (39) and other cancer cells. Within the few last years, a growing interest in the collective effects of chemotherapeutics in combina- 
tion with OOPs was observed. A great number of investigations showed that olive oil phenolic extract (OOPE) and individual OOPs can reduce toxic effects or modulate the activity of chemotherapeutics such as alkylating agents: cisplatin (CP) $(40,41)$, cyclophosphamide (42), dacarbazine (DTIC) (43); plant alkaloids: paclitaxel (44); antitumor antibiotics: mitomycin C (45), doxorubicin (DOX) (46); monoclonal antibodies: trastuzumab (Tzb) (31), cetuximab (47); hormonal agents: tamoxifen (48); enzyme inhibitors: lapatinib (49), vemurafenib (43); antineoplastic and immunomodulating agents: everolimus (43) in different cancer models.

This review reports current knowledge about the chemoprotective and anticancer activity of OOPE and individual OOPs, particularly hydroxytyrosol (HTyr), oleuropein (Ole), oleacein and oleocanthal (Oc) in different types of cancer. Also, the review focuses on the anticancer effect of chemotherapeutics in different cancer cells in combination with OOPE or single OOPs (Ole, Ole aglycone, Oc, HTyr). Results of the studies incorporated in the review could present a novel treatment strategy for cancer chemotherapy.

\section{OLIVE OIL POLYPHENOLS}

OO consists of a glycerol fraction making up $90-99 \%$ of OO and of a minor non-glycerol or unsaponifiable fraction (0.4-5\%) composed of at least thirty-six structurally distinct OOPs. They can be classified according to their similar chemical structure in the following groups: phenolic acids, phenolic alcohols, secoiridoids, hydroxy-isocromans, flavonoids and lignans (50-52). The main source of phenolic compounds is virgin olive oils.

Major OOPs (Fig. 1) include the phenolic alcohols HTyr and their secoiridoid precursors: Ole, oleuropein aglycone (Ole aglycone), oleacin or Oc (53). Levels of individual phenols vary due to natural variability and other factors. For example, median values of HTyr, oleacein, Ole aglycone and Oc obtained for 116 oil samples were 1.9, 185.7, 163.6, $30.7 \mathrm{mg}$ $\mathrm{kg}^{-1}$, respectively (51). These OOPs are deemed to be of central importance for beneficial antioxidant, antiatherogenic and anti-inflammatory, antimicrobial, cardiovascular, neuroprotective and anticancer effects that can be ascribed to the consumption of $O O(24,54)$.
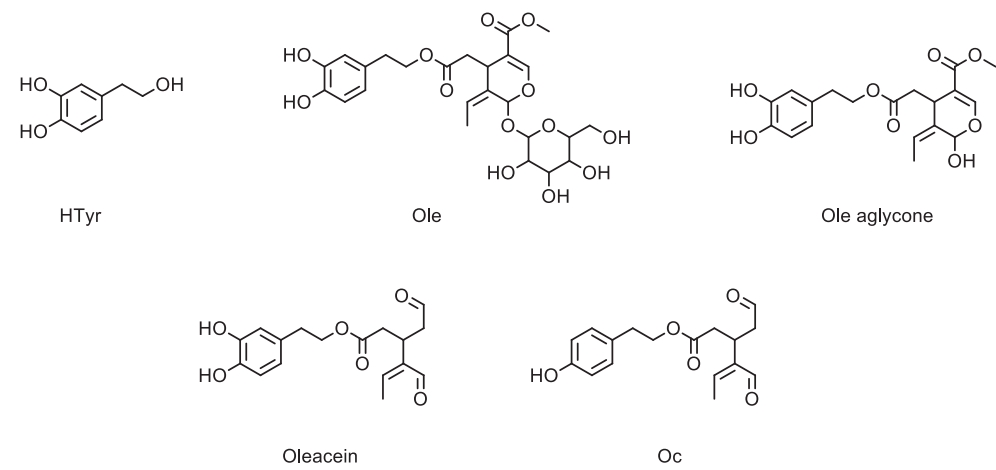

Fig. 1. Chemical structures of major olive oil phenolic compounds used in preclinical studies as anticancer agents. 


\section{ANTICANCER EFFECTS OF OLIVE OIL POLYPHENOLS}

Anticancer activities of OOPs, particularly of phenolic alcohol HTyr and secoiridoid polyphenols Ole and Oc, were largely investigated in the past decades and subsequently reviewed (23, 26, 33, 55-58) (Fig. 2). Apart from recognized potent antioxidant and anti-inflammatory properties, many studies confirmed that these phenolic compounds are able to act on the expression of genes that control proliferation, apoptosis and differentiation of cancer cells $(59,60)$. Possible targets for anticancer effects could be genes that control the production of growth factors (GF) or growth factor receptors (GFR). In normal conditions, binding of GF to its receptor leads to the downstream activation of intracellular signaling mechanisms, some of them being the phosphoinositide 3-kinase (PI3K)/Akt and the mitogen-activated protein kinase (MAPK) signaling pathways, important in control of cell proliferation and inhibition of apoptosis (56). The over-expression of GF or GFR in cancer cells consequently leads to the uncontrolled proliferation and production of signaling molecules that promote the proliferation of neighboring cells and tumor growth (56). OOPs were shown to interfere with these signaling pathways, for example, they can control the phosphorylation state of some signaling molecules, and in that way exert their potential anticancer effects $(33,55,56)$.

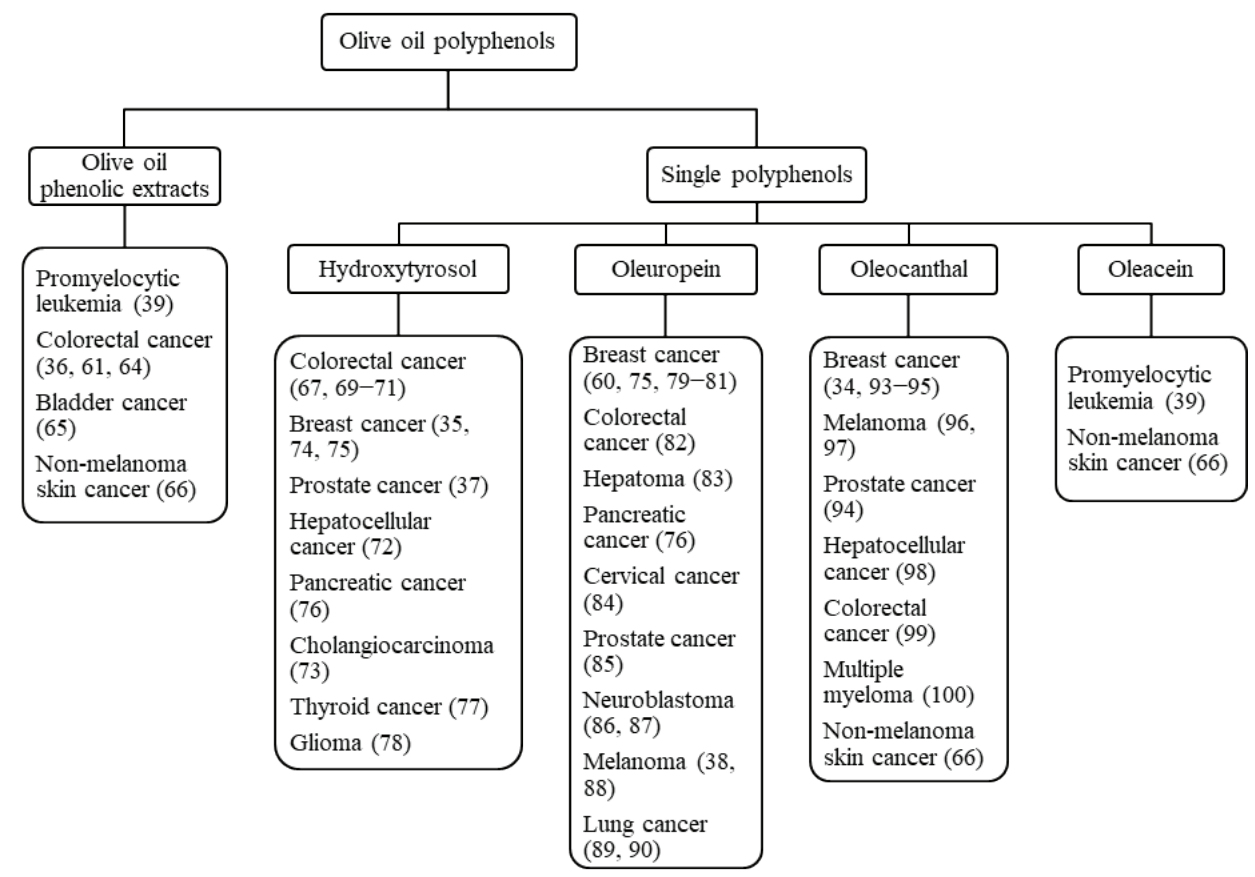

Fig. 2. Schematic panel showing the overview of major olive oil polyphenols used in preclinical studies in different cancer types. 


\section{Anticancer effects of olive oil phenolic extract}

The use of the OOPE instead of a single phenolic compound provides the opportunity for synergistic effects that could be of great interest in anticancer treatment. The anticancer effects of OOPE were investigated in several types of cancer cells. OOPE was shown to prevent from oxidative damage of deoxyribonucleic acid (DNA) in promyelocytic leukemia cells (HL60) (39). The concentrations of polyphenols in the extract were in the range of concentrations that are easily reachable after the usual intake of $\mathrm{OO}$. In colorectal cancer (CRC) studies, OOPE showed in vitro inhibition of some crucial stages in the development of CRC, from initiation to promotion and metastasis (61). OOPE elicited decrease of invasion and spreading of HT115 colon cancer cells and the same effect was translated to the in vivo situation, with a significant decrease of tumor size and metastasis in the mouse model of CRC (36). Those effects were at least partially attributed to the modulation of expression of integrins, cellular adhesion molecules that regulate intra- and inter-cellular signaling. In the mouse model of ulcerative colitis-associated CRC, extra virgin OO diet resulted in reduced incidence and multiplicity of tumors (62). The previous study showed no effect of OO diet in comparison with corn oil diet, on colon carcinogenesis in rats (63). Another in vivo study investigated the effects of extra virgin $\mathrm{OO}$ and its OOPs on gene expression of endocannabinoid system components, via epigenetic regulation, in colon cancer cells and in rats fed with extra virgin $O O$ (59). The results showed a selective and short-term up-regulation of CNR1 gene, a tumor suppressor gene encoding for type 1 cannabinoid receptor $\left(\mathrm{CB}_{1}\right)$, important in the regulation of signaling pathways involved in the control of cell survival and apoptosis. This effect was primarily due to the content of OOPs because the changes in CNR1 methylation and messenger ribonucleic acid (mRNA) levels failed after treatment with extra virgin OO devoid of the OOPs.

Extra virgin OOPE inhibited cell proliferation in colon cancer cells with over-expressed estrogen receptor (ER) $\beta$, and the activation of receptors by OOPs was similar to that of $17 \beta$-estradiol (64). Antimetastatic effects of polyphenols extracted from extra virgin $\mathrm{OO}$ were demonstrated in human transitional bladder cancer cell line T24 (65). This study indicated that OOPE can significantly reduce invasion and migration of bladder cancer cells in vitro, probably by inhibiting matrix metalloproteinase 2 (MMP2), whose over-expression seems to be correlated with poor survival in different cancer types. In the same experimental conditions, normal urothelial fibroblasts were not significantly affected, suggesting that OOPE could be developed as an additional therapy for bladder cancer treatment. The investigation of extra virgin OOPE in non-melanoma skin cancers supported its possible use for topical applications in the prevention and treatment of this type of skin cancers (66).

\section{Anticancer effects of HTyr, Ole, Oleacein, Oc}

HTyr was widely investigated as a possible protective or therapeutic agent in CRC studies and in many others. Although present in relatively low concentrations in OO, HTyr reaches significant levels in large intestine due to the gastric digestion of OO secoiridoids (67). The ability of higher doses of HTyr (usually > $100 \mu \mathrm{M}$ ) to produce reactive oxygen species (ROS), primarily $\mathrm{H}_{2} \mathrm{O}_{2}$, was shown to be at least in part responsible for its antiproliferative and proapoptotic effect (68-70) (Fig. 2). The oxidative stress exhibited by HTyr in human CRC cells activated the PI3K/Akt/FOXO3a (forkhead box O3a) pathway, with the consequent down-regulation of the antioxidant enzymes manganese superoxide dismutase 
(MnSOD) and catalase, but this effect was not noticed in normal colon epithelial cells (69). Contrary, lower doses of HTyr $(<100 \mu \mathrm{M})$ exerted chemo-preventive effect against $\mathrm{H}_{2} \mathrm{O}_{2}$ -induced DNA damage in several types of cancer cell lines, due to its antioxidant ROS-scavenging activity, showing the ability of HTyr to affect the initiation step of carcinogenesis (70). A recent study demonstrated that the antioxidant effect of HTyr is especially effective in a hypoxic environment, characterized by the lower $\mathrm{O}_{2}$ pressure and higher levels of ROS, typical for many solid tumors (35). Furthermore, HTyr was shown to reduce epidermal growth factor receptor (EGFR) levels in CRC cells and in HT-29 xenografts (71). EGFR controls the processes important in cancer's development, such as proliferation, apoptosis, angiogenesis and invasion. The activation of EGFR is followed by its rapid internalization and degradation via both lysosomal and proteasomal mechanisms. HTyr was able to promote EGFR degradation in cancer cells, without affecting the EGFR levels in normal colon cells (71).

HTyr suppressed activation of Akt, nuclear factor kappa B (NF- $k \mathrm{~B})$ and signal transducer and activator of transcription 3 (STAT3) signaling pathways in prostate cancer (PC) cell lines, all of them being important in proliferation, invasion and metastasis of cancer cells, and progression to aggressive castration-resistant PC (37). Suppression of Akt and NF- $\kappa B$ pathways by HTyr was also observed in the study of human hepatocellular carcinoma (HCC), both in vitro and in vivo, in the orthotopic mouse model of human HCC (72). Transcription factor NF- $\kappa \mathrm{B}$, whose activation is ubiquitous in most of the malignant tumors, is involved in proliferation, apoptosis, invasion, angiogenesis, metastasis and chemoresistance of many tumors, and therefore, this effect of HTyr could be particularly significant. HTyr was studied in cholangiocarcinomas (CCA), a group of cancers that form in bile ducts and are associated with poor prognosis (73). The HTyr treatment induced apoptosis by multiple pathways in CCA cells and significant suppression of tumor growth in the mouse xenografts. This effect was due to the inhibition of extracellular signal-regulated kinase (ERK), another signaling pathway of crucial importance in cancer growth and development. The anticancer effects of HTyr were also investigated in BC $(35,74,75)$, pancreatic cancer (76), human papillary and follicular thyroid cancer (77) and glioma (78), results that are worthy of further investigations.

Ole, a secoiridoid OOP, showed many beneficial anticancer properties in a great number of studies, especially in the case of BC (Fig. 2). One study showed that Ole and HTyr are capable of binding and activating G-protein-coupled receptor (GPER), a different type of ER, and cause a sustained ERK 1/2 activation leading to an apoptotic effect in ER-negative BC cells (75). Proapoptotic Bax protein up-regulation and a decrease in anti-apoptotic Bcl-2 expression, together with the induction of GPER-dependent cytosolic cytochrome c release, revealed the mitochondrial apoptotic mechanism, which was activated by Ole and HTyr. Moreover, caspase-9, caspase-3 cleavage as well as peroxisome proliferator-activated receptor 1 (PARP-1) inactivation supported the proposed mitochondrial apoptotic pathway. The same study showed the up-regulation of $\mathrm{p} 21$ and p53 proteins, negative regulators of the cell cycle, and a reduction in cyclin D1 expression after the Ole treatment $(75,79,80)$. In another study, the proapoptotic effect of Ole via mitochondrial pathway showed more than 10 times greater effect on ER-negative cells in comparison to ER-positive cells (79). Furthermore, Ole was able to induce the antimetastatic effect in human BC cells due to the regulation of certain genes encoding for MMPs and tissue inhibitors of metalloproteinases (TIMPs) (60). MMP enzymes indeed facilitate the invasion of cancer cells and are respon- 
sible for distant metastases, while their inhibitors TIMPs are often decreased in cancers. Furthermore, Ole showed the inhibition of growth of MCF-7 human breast tumor xenografts and significant reduction of their invasiveness into the lung (81).

The first study demonstrating the effect of Ole on HT-29 colon cancer cells showed induction of apoptosis by p53-dependent mechanism adapting the hypoxia-inducible factor $1 \alpha$ (HIF-1 $\alpha$ ) response to hypoxia (82). HIF-1 $\alpha$, usually increased in many human cancers due to the genetic alterations and intratumoral hypoxia, was significantly decreased after Ole treatment. The investigation of anticancer effects of Ole in human hepatoma cells showed the suppression of PI3K/Akt pathway, possibly because of augmented intracellular ROS levels induced by Ole (83). Furthermore, Ole treatment caused the alteration in the Bax/ $\mathrm{Bcl}-2$ ratio, correlated with the aforementioned apoptosis through a mitochondrial pathway. In the case of pancreatic cancer, Ole selectively reduced the viability, caused cell cycle arrest and induced apoptosis via several different pathways in MiaPaCa-2 cells, without affecting normal pancreas cells (76).

The anticancer effects of Ole were also examined in vitro in human cervical cancer cells (84), PC cells (85), and neuroblastoma cells $(86,87)$ and in vivo in the melanoma mouse model $(38,88)$, with promising results. Two very recent studies demonstrated the beneficial effects of Ole in different types of lung cancers $(89,90)$. The diversity of Ole's anticancer properties renders it a potential natural therapeutic in the future treatment of these malignant diseases.

The anticancer effects of Oc were largely researched in the past decade. As a naturally occurring cyclooxygenase (COX) inhibitor, Oc possesses anti-inflammatory properties important for the treatment of some cancers as well $(91,92)$ (Fig. 2). Oc is also an inhibitor of hepatocyte growth factor/c-mesenchymal-epithelial transition factor (HGF/c-Met) signaling pathway, whose dysregulation is included in many important stages of cancer development and growth, some of them being cell proliferation and survival, epithelial-to-mesenchymal transition, angiogenesis and metastasis of cancer cells (93). Due to this activity, Oc was able to inhibit the proliferation, migration, and invasion of non-metastatic and highly metastatic human BC and PC cell lines and the tumor growth in BC animal model $(93,94)$. Also, Oc treatment caused a marked down-regulation of phosphorylated mammalian target of rapamycin (mTOR) in metastatic BC cell line (34). Oc impaired the ability of BC cells to proliferate and migrate via down-regulation of TRPC6 (transient receptor potential cation channel) $\mathrm{Ca}^{2+}$ channel expression, in a very aggressive triple-negative type of $\mathrm{BC}$ (95).

Furthermore, Oc showed remarkable effects in malignant melanoma cancers. Oc was cytotoxic in low $\mu \mathrm{M}$ concentrations against human melanoma cells with no effect on normal dermal fibroblasts (96). In this study, both ERK and Akt phosphorylation were significantly reduced, pointing to a possible mechanism that may lead to suppression of melanoma cell growth induced by Oc. In vivo study on melanoma cells showed that Oc could inhibit STAT3 signaling pathway, involved in apoptosis, invasion and angiogenesis of melanoma cells, and the tumor growth and metastases of melanoma as well (97).

Blocking of STAT3 signaling pathway by Oc was responsible for the antiproliferative and proapoptotic effect in HCC cells in vitro, as well as for the suppression of tumor growth and reduction of lung metastases in vivo (98). The anticancer effects of Oc were also demonstrated in CRC (99) and multiple myeloma (100) cells suggesting the possible role of Oc in the treatment of these malignant diseases. 
The literature on anticancer effects of oleacein is not so abundant as for Hyr, Ole and Oc, but several cancer studies confirmed some beneficial effects worth of mentioning. In HL60 promyelocytic leukemia cells oleacein reduced the DNA damage when co-incubated in the medium with $\mathrm{H}_{2} \mathrm{O}_{2}$ (39). Also, oleacein and Oc separately reduced the viability and migration of non-melanoma skin cancer cells and inhibited proliferation of atypical keratinocytes stimulated with EGF. This effect was carried through the inhibition of ERK and Akt phosphorylation and particularly through the reduction of B-Raf expression (66) (Fig. 2). This study was the first evidence of the in vitro capability of oleacein to induce apoptosis in non-melanoma skin cancer cells through inhibition of key signaling pathway.

Much effort has been made to find or synthesize a novel OOP lipophilic derivatives and analogs with improved stability and enhanced biological properties (101-103). The antioxidant, antiproliferative and anti-inflammatory effects of some HTyr derivatives suggested a greater activity in cancer chemoprevention and preclinical treatment, in comparison with the parental HTyr (102). Lipophilized natural extracts containing HTyr showed an antiproliferative effect on the human CRC cells, with the greatest effect of HTyr-oleate fraction, probably due to the major lipophilicity of the oleate chain (103). A peracetylated derivative of Ole (Ac-Ole) was evaluated against thyroid tumor cell lines demonstrating significant inhibition of cell growth (104). Ac-Ole elicited stronger effect in comparison with Ole, probably because of its improved permeability. In the case of $\mathrm{BC}$, the antiproliferative effects of Ole's peracetylated compounds were higher than Ole's, due to a stronger antioxidant activity (105). The development of semisynthetic bioisostere analogues of Oc was encouraged by its c-Met inhibitory activity as well as antimetastatic activity. Tyr-sinapate showed antimigratory, antiproliferative, and anti-invasive effects in metastatic BC without cytotoxicity to the normal epithelial breast cells (106). Also, another Oc-based c-Met inhibitor named homovanillyl sinapate showed a significant reduction in tumor growth and angiogenesis, without any sign of toxicity, in an orthotopic mouse model of triple negative BC (107).

\section{ANTICANCER EFFECTS OF OLIVE OIL POLYPHENOLS COMBINED WITH ANTICANCER DRUGS}

\section{Olive oil phenolic extract combined with anticancer drugs}

Numerous studies have shown that individual OOPs could interact with certain anticancer drugs, thus indicating the considerable potential of the combination of OOPE and conventional chemotherapy in cancer treatment. These combinations may be helpful in the case of drug resistance and prevent or alleviate the side effects of anticancer therapy (108).

When tested in a complex mixture such as extra virgin OOPE, polyphenols have a stronger chemopreventive effect in comparison with individual compounds, and this effect may be the consequence of the synergistic effect of the components (109). However, caution should be required, because the combination of extra virgin OOPE and chemotherapeutic drugs may generate various outcomes, including synergism and antagonism.

Coccia et al. (45) have investigated the interaction of extra virgin OOPE with anticancer drugs paclitaxel or mitomycin $C$ in vitro. Paclitaxel is a mitotic inhibitor indicated in the therapy of several types of cancer including bladder cancer (110). Mitomycin C inhibits DNA synthesis and it is often used in the chemotherapy of bladder cancer cells (111). Dif- 
ferent doses of mitomycin C or paclitaxel were used in the treatment of T24 cells, in the presence or absence of the OOPE. The data showed that OOPE reduces the antiproliferative ability of mitomycin C. Although $100 \mathrm{mg} \mathrm{ml}^{-1}$ of mitomycin C strongly increased intracellular ROS production in T24 cells, the co-treatment with OOPE attenuated this effect. Opposite of that, OOPE strongly increased paclitaxel cytotoxicity. In the presence of the OOPE, $5 \mathrm{nM}$ paclitaxel exerted the same cytotoxicity as $100 \mathrm{nM}$ paclitaxel alone. Paclitaxel alone did not induce oxidative stress, whereas the co-treatment with OOPE reduced basal ROS production. It was assumed that the increased cytotoxicity of paclitaxel could be associated with a change in gene expression, engaged in cell growth and proliferation, via the plateletactivating factor (PAF) receptor signaling or PI3K signaling (45).

\section{Olive oil polyphenols combined with anticancer drugs}

The influence of OO characteristic phenolic compounds, Ole, Oc, Ole aglycone and HTyr on the effects of conventional anticancer drugs attracts a great deal of attention nowadays (26). There are a few studies concerning the effects of combined treatment with Ole and $\mathrm{CP}$ on $\mathrm{CP}$-induced toxicities. $\mathrm{CP}$ belongs to the first generation of anticancer drugs, and it is widely used in the chemotherapy of many cancers. Despite its effectiveness, the major limitations of CP use in therapy are serious side effects as the development of drug-resistance and acute nephrotoxicity, noticed in $20-30 \%$ of patients (112). Renal injury is the consequence of oxidative and inflammatory processes. Concomitant use of various natural compounds with antioxidant and anti-inflammatory properties have been proposed for the prevention. It was shown that Ole attenuates CP-induced acute renal injury in a male BALB/c mouse model (40) (Table I). In this study the mice were divided in six groups: control group, a group treated with Ole alone $\left(20 \mathrm{mg} \mathrm{kg}^{-1}\right.$, orally), a group treated with $\mathrm{CP}$ alone (13 $\mathrm{mg} \mathrm{kg}^{-1}$, intraperitoneally (i.p.)), and three groups treated firstly with $\mathrm{CP}$, and after 48 hours with Ole $\left(5,10,20 \mathrm{mg} \mathrm{kg}^{-1}\right)$ for two days. The kidney tissue of the groups treated with $\mathrm{CP}$ alone, $\mathrm{CP}+\mathrm{Ole}$ and control group were compared. In the control group and the $\mathrm{CP}+\mathrm{Ole}$ group, normal kidney morphology was observed, whereas in the group treated with $\mathrm{CP}$ there was tubular necrosis. According to biochemical parameters, the protective effect of Ole was connected to the decreased ERK 1/2 activation and ERK-dependent inflammatory response, apoptosis and antioxidant enzyme expression.

Another study analyzed the combined treatment with Ole and CP in human HCC HepG2 cells (41). The first line of cells were treated with CP alone (20, 50 and $100 \mu \mathrm{M})$, the second line with Ole alone $(100,200,300$ and $400 \mu \mathrm{M})$ and the third line with the combination of $\mathrm{CP}(50 \mu \mathrm{M})$ and Ole $(100,200,300$ and $400 \mu \mathrm{M})$. Gene expression of nerve growth factor (NGF), MMP-7, caspase-3, the concentration of NO, NGF and pro-NGF were compared. In cells treated with $\mathrm{CP}+\mathrm{Ole}$, the toxic effects were reduced, and the most effective combination was with $200 \mu \mathrm{M}$ Ole (41). Also, the effect of Ole on CP-induced liver damages in male Sprague-Dawley rats was investigated (113). Control group was treated with CP

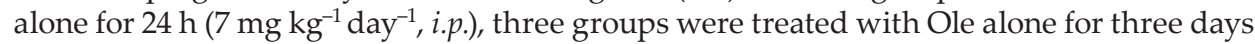
$\left(50,100\right.$, and $200 \mathrm{mg} \mathrm{kg}^{-1}$, i.p.), and three groups were treated with the combination of CP and Ole, CP (7 mg kg-1 $\mathrm{day}^{-1}$, i.p. $)$ and after 24 hours Ole (50, 100, and $200 \mathrm{mg} \mathrm{kg}^{-1}$, i.p.). In the group treated with $\mathrm{CP}$ alone, the whole liver tissue showed significant histological damages, increased incidence of oxidative stress, the induction of 8-hydroxy-2'-deoxyguanosine (8-OHdG), and abnormal results on liver function tests. Administration of Ole alleviated liver injury and the biochemical parameters reached the normal values. The dose of $200 \mathrm{mg}$ 
Table I. Olive oil polyphenols and their combinations with anticancer drugs in preclinical cancer models

\begin{tabular}{|c|c|c|c|c|}
\hline $\begin{array}{l}\text { Phenolic } \\
\text { compounds }\end{array}$ & Anticancer drug & Experimental models & Effects of OOPs & References \\
\hline \multirow[b]{2}{*}{ OOPE } & Paclitaxel & \multirow[b]{2}{*}{$\begin{array}{l}\text { Bladder cancer cells } \\
\text { (T24 and 5637) }\end{array}$} & Synergistic & \multirow[b]{2}{*}{$(45)$} \\
\hline & Mitomycin C & & $\begin{array}{c}\text { Reduced drug } \\
\text { cytotoxicity }\end{array}$ & \\
\hline Ole & Cisplatin & Male BALB/c mouse model & Renoprotective & (40) \\
\hline Ole & Cisplatin & Male Sprague-Dawley rats & Liver protective & (113) \\
\hline Ole & Cisplatin & $\begin{array}{l}\text { Hepatocellular carcinoma } \\
\text { cells }\end{array}$ & $\begin{array}{c}\text { Reduction of toxic } \\
\text { effect }\end{array}$ & (41) \\
\hline Ole & Cisplatin & Sprague-Dawley rats & $\begin{array}{l}\text { Stomach and lung } \\
\text { protective }\end{array}$ & (114) \\
\hline Ole & Cisplatin & Sprague-Dawley rats & Pancreas protective & (115) \\
\hline Ole or HTyr & Cisplatin & Water solution & $\begin{array}{l}\text { Form conjugate with } \\
\text { drug in water } \\
\text { solution }\end{array}$ & (116) \\
\hline Ole aglycone & Trastuzumab & $\begin{array}{c}\text { Human breast cancer cells } \\
\text { (SKBR3) }\end{array}$ & Synergistic & (31) \\
\hline Oc & Tamoxifen & $\begin{array}{l}\text { Luminal breast cancer cells } \\
\text { (HER-2 positive BT474) }\end{array}$ & Synergistic & $(48)$ \\
\hline Oc & Lapatinib & $\begin{array}{l}\text { Breast cancer cells (HER-2 } \\
\text { positive BT474 and SKBR3) }\end{array}$ & Synergistic & $(49)$ \\
\hline HTyr & Paclitaxel & $\begin{array}{c}\text { Breast cancer cells } \\
\text { (MCF-7, MDA-MB-231) }\end{array}$ & Synergistic & $(44)$ \\
\hline HTyr & Paclitaxel & $\begin{array}{l}\text { Breast cancer in female } \\
\text { Sprague-Dawley rats }\end{array}$ & $\begin{array}{l}\text { Reduced drug } \\
\text { cytotoxicity }\end{array}$ & $(44)$ \\
\hline Ole & Doxorubicin & $\begin{array}{l}\text { Human breast cancer cells } \\
\text { (MDA-MB231) in female } \\
\text { nude BALB/c mice }\end{array}$ & Synergistic & $(46)$ \\
\hline HTyr & Cetuximab & $\begin{array}{l}\text { Colon cancer cells } \\
\text { (HT-29 and WiDr) }\end{array}$ & $\begin{array}{l}\text { Reduction of toxic } \\
\text { effect }\end{array}$ & $(47)$ \\
\hline Ole & $\begin{array}{c}\text { Dacarbazine } \\
\text { Everolimus } \\
\text { Vemurafenib }\end{array}$ & $\begin{array}{l}\text { Human melanoma cells } \\
\text { (A375) }\end{array}$ & $\begin{array}{c}\text { Synergistic } \\
\text { Synergistic } \\
\text { No effect }\end{array}$ & (43) \\
\hline Ole or QT & $\begin{array}{c}\text { Cyclo- } \\
\text { phosphamide }\end{array}$ & Male Winstar rats & $\begin{array}{l}\text { Reduced drug } \\
\text { cytotoxicity }\end{array}$ & $(42)$ \\
\hline Ole & 2-metoxyestradiol & Human osteosarcoma cells & Synergistic & (117) \\
\hline
\end{tabular}

$\mathrm{kg}^{-1}$ showed the optimal protective effect. The same experimental design was used to test the effects of combined treatment of Ole and $\mathrm{CP}$ on stomach and lung injuries induced by CP (114) and CP-induced pancreas toxicity (115). It was shown that the addition of a high 
dose of Ole to animals treated with $\mathrm{CP}$ exerts a protective effect. $\mathrm{CP}$ increased 8-OHdG, malondialdehyde (MDA) and total oxidative stress (TOS) and also caused severe tissue damages, while Ole $\left(200 \mathrm{mg} \mathrm{kg}^{-1}\right)$ decreased these parameters and improved tissue damages. In addition, the interaction between Ole and HTyr with hydrated CP was investigated by the use of reverse-phase liquid chromatography coupled to electrospray ionization and mass spectrometry (RPLC-ESI-MS) and by MS/MS measurements (116). Hydrated CP is the active form of $\mathrm{CP}$, with labile chloride ligands in CP complex exchanged by water. This complex binds to DNA purine base forming adduct which inhibits transcription and finally kills the cancerous cell. This study shows that Ole or HTyr and hydrated CP form conjugate in water solution, what could be of interest when considering the mechanisms by which they might contribute to reducing CP-induced toxicity (116).

Besides the effect of Ole on CP therapy, the effects of combined treatment of other OOPs with various anticancer agents were also studied. Among the first combinations was the one of Ole aglycone with trastuzumab (Tzb), the monoclonal antibody (31). The study was conducted in the human SKBR3 BC cell line characterized by human epidermal growth factor receptor 2 (HER-2) expression. HER-2 is a proto-oncogene with an important role in cancer development and treatment failure in BC disease. Tzb blocks HER-2 expression and activity by reduction of HER-2 extracellular domain cleavage and its subsequent autophosphorylation. In this study the same mechanism was reported for Ole aglycone, and also the synergistic Tzb and Ole aglycone activity. Ole aglycone enhanced Tzb-induced down-regulation of HER-2 expression and induced up to a 50-fold increase in the efficacy of Tzb. A cell line with acquired autoresistance to Tzb (SKBR3/Tzb100 cells), treated with Ole aglycone, led to the recovery of the Tzb sensitivity. This is of importance to circumvent Tzb resistance in $\mathrm{BC}$ disease and could be of clinical relevance.

The combined treatments of phenolic compound Oc and anticancer drugs used in BC therapies was studied. Among them was the combination of Oc and anti-estrogen tamoxifen (Tmx), investigated in a luminal BC cell line (BT474), characterized by HER-2 expression and, estrogen and progesterone receptors (48). Luminal BCs account for about $60 \%$ of all BCs. Conventional treatment for luminal B tumors is anti-HER-2 and endocrine therapy, although luminal B tumors show resistance to anti-HER-2 targeted therapies and reduced sensitivity to endocrine treatment. In this study, Oc and Tmx act synergistically probably due to their different binding modes at the ERs site. Another investigated combination was Oc and lapatinib (49). Combined treatment with Oc and lapatinib was studied in HER-2-positive BT-474 and SK-BR-3 BC cell lines. Lapatinib is an EGFR/HER-2 inhibitor for HER-2-amplified BC. Dysregulation of EGFR/HER-2 family is a feature of aggressive BC, while the anticancer activity of Oc is associated with c-Met. The combined treatment elicited the synergistic anti-proliferative effect, compared to Oc or lapatinib monotherapy. The combination significantly inhibited EGFR, HER-2, and c-Met receptor activation, as well as downstream signaling proteins, and inhibited invasion and migration of BC cells. Oc (10 mg $\mathrm{kg}^{-1}$ ) and lapatinib (12.5 $\left.\mathrm{mg} \mathrm{kg}^{-1}\right)$ suppressed more than $90 \%$ of BT-474 tumor cells growth, compared to Oc or lapatinib monotherapy. The future potential of combination therapy was suggested as it sensitizes HER-2-overexpressing BCs and significantly reduces required doses of targeted HER family therapeutics. Recently, the combination of HTyr and paclitaxel was studied in in vitro and in vivo BC models (44). Paclitaxel generates a very high redox imbalance, promoting damage to both tumor and healthy cells. The impact of the combination of HTyr and paclitaxel on proliferation rates was assayed in MCF-7 and 
MDAMB-BC cell lines. The combined treatment was more efficient than paclitaxel alone. In vivo model of BC, female Sprague-Dawley rats with chemically 7,12-dimethylbenz(a)anthracene (DMBA) induced cancer, characterized by estrogen overexpression, was treated for 6 weeks to test the effect of this combination. In the case of combined treatment, the tumor volume was significantly reduced in comparison with paclitaxel alone. The combination improved the antioxidant status and in that way compensated the adverse effects. This combination possibly allows lower drug doses, with reduced side effects. Another study investigated the effects of the combination of Ole and DOX on breast tumor xenografts in in vitro and in vivo models (46). Female nude mice were injected subcutaneously with human BC cells MDA-MB231. After the growth of tumors, the animals were divided into 4 groups: a control group, a group treated with Ole $\left(50 \mathrm{mg} \mathrm{kg}^{-1}\right)$, a group treated with DOX $\left(2.5 \mathrm{mg} \mathrm{kg}^{-1}\right)$ and a group treated with the combination of DOX $\left(1.5 \mathrm{mg} \mathrm{kg}^{-1}\right)$, immediately followed by Ole $\left(50 \mathrm{mg} \mathrm{kg}^{-1}\right)$. A xenograft tumor was characterized by low or no expression of HER-2, estrogen and progesterone. In the group with combined treatment, a more than 3 -fold decrease in the volume of the tumor was observed. The effect was connected with the mitochondrial pathway and the induction of apoptosis.

The effect of the combination of HTyr and anticancer drug cetuximab was studied in colon cancer in vitro model (47). The growth of colon tumors, as well as several other epithelial human cancers of the digestive tract, is connected with signaling pathways triggered by EGF. HTyr down-regulates EGF receptor (EGFR) expression and cell proliferation in colon cancer cells, similarly as cetuximab, monoclonal antibody currently used in the treatment of colon cancers. The effects of combined treatment with HTyr and cetuximab were investigated in HT-29 and WiDr colon cancer cells. The combination reduced cell proliferation at a concentration 10 times than the one used as monotherapy. The combined treatment induced a marked down-regulation of EGFR levels, and mitochondrial dysfunction leading to cell cycle arrest and apoptosis, but to a very small extent affected the normal human colon and skin cells, suggesting that the combined therapy might attenuate cetuximab side effects, as skin toxicity and diarrhea.

The effects of combined treatment with Ole and conventional drugs used to treat BRAF melanoma were also investigated (43). Melanoma is the major cause of skin cancer-related deaths and about $50-60 \%$ of melanomas show the BRAF mutation, which implies the activation of ERK signaling, leading to an increase of proliferation and transformation. The effect of combined treatment was analyzed in A375 human melanoma cells. Ole increased the cytotoxic effect of DTIC, which is considered the main drug for the treatment of the advanced stage of melanoma, at $250 \mu \mathrm{M}$ concentration, and potentiated the effect of everolimus (RAD001), possibly through the inhibition of the pAKT/pS6 pathway, while it showed no effect on vemurafenib (PLX4032) at a $250 \mu \mathrm{M}$ concentration.

Ole and quercetin (QT) combination with cyclophosphamide (Cyclo) in Cyclo-induced hepatotoxicity in male Wistar rats was investigated (42). Cyclo is a cytotoxic oxazaphosphorine alkylating agent that requires activation in the liver. It has been used in the therapy of a variety of cancers, especially lymphoma, and also as an immunosuppressive drug, with serious side effects, as hepatotoxicity. In the rat group which received Cyclo alone, alkaline phosphatase, serum transaminase, tumor necrosis factor-alpha (TNF- $\alpha$ ) and hepatic MDA were significantly increased, superoxide dismutase (SOD) and hepatic reduced glutathione catalase levels were significantly reduced, hepatic nuclear factor erythroid 2-related factor 2 (Nrf2) and heme oxygenase-1 (HO-1) expressions were down-regulated and reduction in 
hepatic nuclear Nrf2 binding activity and hepatic tissue damage were observed. In rat groups which were treated with combined therapy, Cyclo+Ole or Cyclo+QT, both Ole and QT exhibited an improvement in the biochemical and histopathological findings, connected with attenuation of oxidative stress and inflammation, via Nrf2/HO-1 signaling pathway.

A recent study analyzed the effects of combined treatment with Ole and 2-methoxyestradiol (2-ME), in highly metastatic osteosarcoma (OS) cells, 143B OS (117). Ole exerts anti-migratory and anti-proliferative effects on human OS cells. In the case of treatment with Ole alone and in combination with 2-ME, the induction of autophagy and/or induction of nitro-oxidative stress was observed.

The reduced effectiveness of chemotherapeutics is attributed, among others, to their inappropriate pharmacokinetic features as poor penetration into the tumor microenvironment and toxicity to healthy cells. One approach which tries to resolve this problem is the development of targeted nanotherapeutics (118). The formulation of co-encapsulated QT, a flavonoid present in OO, with Tmx in orally administrable poly(lactic-co-glycolic acid)nanoparticles (PLGA-NPs) showed significantly higher tumor suppression in comparison to the treatment with QT or Tmx alone, but also to their combination, in DMBA induced BC model in female rats (119). This could be a promising perspective when considerating combined treatments with OOPs and anticancer drugs.

\section{CONCLUSIONS}

An ideal drug for cancer chemotherapy must exhibit high levels of cytotoxicity with negligible side effects. The results of in vitro and in vivo studies reported that OOPs have a high potential as chemopreventive and anticancer agents. A combination of OOPs with anticancer drugs may offer a better strategy for cancer treatment, due to the improvement of chemotherapy efficacy and reduction of toxic effects. Although the described preclinical studies confirm the beneficial effects of OOPs alone and combined with anticancer drugs, their efficacy remains to be proven in humans.

Abbreviations, acronyms, symbols. - 2-ME - 2-methoxyestradiol, 8-OHdG - 8-hydroxy-2'deoxyguanosine, $\mathrm{BC}$ - breast cancer, $\mathrm{CB}_{1}$ - cannabinoid receptor, $\mathrm{CCA}$ - cholangiocarcinoma, c-Met - mesenchymal-epithelial transition factor, COX - cyclooxygenase, $\mathrm{CP}$ - cisplatin, CRC - colorectal cancer, Cyclo - cyclophosphamide, DMBA - 7,12-dimethylbenz(a) anthracene, DNA - deoxyribonucleic acid, DOX - doxorubicin, DTIC - dacarbazine, EFSA - European Food Safety Authority, EGF - epidermal growth factor, EGFR - epidermal growth factor receptor, ER - estrogen receptor, ERK- extracellular signal-regulated kinase, FOXO3a - forkhead box O3a, GF - growth factor, GFR - growth factor receptor, GLOBOCAN 2018 - global burden of cancer 2018 database, GPER - G-protein-coupled receptor, HCC - hepatocellular carcinoma, HER-2 - human epidermal growth factor receptor 2, HGF - hepatocyte growth factor, HIF-1 $\alpha$ - hypoxia-inducible factor- $1 \alpha$, HO-1- heme oxygenase-1, HTyr - hydroxytyrosol, i.p. - intraperitoneally, IARC - International Agency for Research on Cancer, MAPK - mitogen activated protein kinase, MD - Mediterranean diet, MDA malondialdehyde, MMP - matrix metalloproteinase, MnSOD - manganese superoxide dismutase, mRNA - messenger ribonucleic acid, mTOR - mammalian target of rapamycin, $\mathrm{NF}-\kappa \mathrm{B}$ - nuclear factor kappa B, NGF - nerve growth factor, Nrf2 - nuclear factor erythroid 2-related factor 2, Oc - oleocanthal, Ole - oleuropein, Ole aglycone - oleuropein aglycone, 
OO - olive oil, OOP - olive oil polyphenol, OOPE - olive oil phenolic extract, OS - osteosarcoma, PAF - platelet-activating factor, PARP-1 - peroxisome proliferator-activated receptor 1, PC - prostate cancer, PI3K - phosphoinositide 3-kinase, PLGA-NPs - poly(lactic-co-glycolic acid)-nanoparticles, QT - quercetin, ROS - reactive oxygen species, SOD - superoxide dismutase, STAT3 - signal transducer and activator of transcription 3, TIMP - tissue inhibitor of metalloproteinase, Tmx - tamoxifen, TNF- $\alpha$ - tumor necrosis factor-alpha, TOS total oxidative stress, TRPC6 - transient receptor potential cation channel, Tyr - tyrosol, Tzb - trastuzumab.

\section{REFERENCES}

1. WHO Cancer, WHO.; Accessed May 21, 2019, from http://www.who.int/cancer/en/

2. What Is Cancer?, National Cancer Institute; Accessed May 21, 2019, from https://www.cancer.gov/ about-cancer/understanding/what-is-cancer

3. N. A. Lobo, Y. Shimono, D. Qian and M. F. Clarke, The biology of cancer stem cells, Annu. Rev. Cell Dev. Biol. 23 (2007) 675-699; https://doi.org/10.1146/annurev.cellbio.22.010305.104154

4. F. Bray, J. Ferlay, I. Soerjomataram, R. L. Siegel, L. A. Torre and A. Jemal, Global cancer statistics 2018: GLOBOCAN estimates of incidence and mortality worldwide for 36 cancers in 185 countries, CA-Cancer J. Clin. 68 (2018) 394-424; https://doi.org/10.3322/caac.21492

5. T. Nabekura, Overcoming multidrug resistance in human cancer cells by natural compounds, Toxins 2 (2010) 1207-1224; https://doi.org/10.3390/toxins2061207

6. M. Fantini, M. Benvenuto, L. Masuelli, G. Frajese, I. Tresoldi, A. Modesti and R. Bei, In vitro and in vivo antitumoral effects of combinations of polyphenols, or polyphenols and anticancer drugs: perspectives on cancer treatment, Int. J. Mol. Sci. 16 (2015) 9236-9282; https://doi.org/10.3390/ ijms16059236

7. The 10 most common chemotherapy side effects, Medical News Today.; Accessed May 21, 2019, from https://www.medicalnewstoday.com/articles/323485.php

8. U. Lewandowska, S. Gorlach, K. Owczarek, E. Hrabec and K. Szewczyk, Synergistic interactions between anticancer chemotherapeutics and phenolic compounds and anticancer synergy between polyphenols, Postepy. Hig. Med. Dosw. (Online) 68 (2014) 528-540.

9. C. Manach, G. Williamson, C. Morand, A. Scalbert and C. Rémésy, Bioavailability and bioefficacy of polyphenols in humans. I. Review of 97 bioavailability studies, Am. J. Clin. Nutr. 81 (2005) 230S242S; https://doi.org/10.1093/ajcn/81.1.230S

10. G. Williamson and C. Manach, Bioavailability and bioefficacy of polyphenols in humans. II. Review of 93 intervention studies, Am. J. Clin. Nutr. 81 (2005) 243S-255S; https://doi.org/10.1093/ ajcn/81.1.243S

11. H.-H. S. Chow and I. A. Hakim, Pharmacokinetic and chemoprevention studies on tea in humans, Pharmacol. Res. (2011) S1043661811001435; https://doi.org/10.1016/j.phrs.2011.05.007

12. A. Rodriguez-Mateos, D. Vauzour, C. G. Krueger, D. Shanmuganayagam, J. Reed, L. Calani, P. Mena, D. Del Rio and A. Crozier, Bioavailability, bioactivity and impact on health of dietary flavonoids and related compounds: an update, Arch. Toxicol. 88 (2014) 1803-1853; https://doi. org/10.1007/s00204-014-1330-7

13. T. M. de Kok, S. G. van Breda and M. M. Manson, Mechanisms of combined action of different chemopreventive dietary compounds: A review, Eur. J. Nutr. 47 (2008) 51-59; https://doi.org/10.1007/ s00394-008-2006-y

14. H. Wagner, Synergy research: Approaching a new generation of phytopharmaceuticals, Fitoterapia 82 (2011) 34-37; https://doi.org/10.1016/j.fitote.2010.11.016 
15. K. Nurgali, R. T. Jagoe and R. Abalo, Editorial: Adverse effects of cancer chemotherapy: Anything new to improve tolerance and reduce sequelae?, Front. Pharmacol. 9 (2018) 245; https://doi. org/10.3389/fphar.2018.00245

16. D. Shukla, R. Rawal and N. Jain, A brief review on plant-derived natural compounds as an anticancer agents, Int. J. Herbal Med. 6 (2018) 28-36.

17. A. K. Garg, T. A. Buchholz and B. B. Aggarwal, Chemosensitization and radiosensitization of tumors by plant polyphenols, Antioxid. Redox Signal. 7 (2005) 1630-1647; https://doi.org/10.1089/ ars.2005.7.1630

18. H. Yang, K. Landis-Piwowar, D. Chen, V. Milacic and Q. Dou, Natural compounds with proteasome inhibitory activity for cancer prevention and treatment, Curr. Protein Pept. Sci. 9 (2008) 227239; https://doi.org/10.2174/138920308784533998

19. L. G. Korkina, C. De Luca, V. A. Kostyuk and S. Pastore, Plant polyphenols and tumors: from mechanisms to therapies, prevention, and protection against toxicity of anti-cancer treatments, Curr. Med. Chem. 16 (2009) 3943-3965; https://doi.org/10.2174/092986709789352312

20. J. Węsierska-Gądek, M. P. Kramer and M. Maurer, Resveratrol modulates roscovitine-mediated cell cycle arrest of human MCF-7 breast cancer cells, Food Chem. Toxicol. 46 (2008) 1327-1333; https://doi.org/10.1016/j.fct.2007.09.004

21. W. Zhou, X. Feng, Han Han, S. Guo and G. Wang, Synergistic effects of combined treatment with histone deacetylase inhibitor suberoylanilide hydroxamic acid and TRAIL on human breast cancer cells, Sci. Rep. 6 (2016); https://doi.org/10.1038/srep28004

22. C.-G. Wang, W.-N. Yao, B. Zhang, J. Hua, D. Liang and H.-S. Wang, Lung cancer and matrix metalloproteinases inhibitors of polyphenols from Selaginella tamariscina with suppression activity of migration, Bioorg. Med. Chem. Lett. 28 (2018) 2413-2417; https://doi.org/10.1016/j.bmcl.2018.06.024

23. R. Fabiani, Anti-cancer properties of olive oil secoiridoid phenols: a systematic review of in vivo studies, Food Funct. 7 (2016) 4145-4159; https://doi.org/10.1039/C6FO00958A

24. L. Parkinson and S. Cicerale, The health benefiting mechanisms of virgin olive oil phenolic compounds, Molecules 21 (2016) 1734; https://doi.org/10.3390/molecules21121734

25. M. Gorzynik-Debicka, P. Przychodzen, F. Cappello, A. Kuban-Jankowska, A. Marino Gammazza, N. Knap, M. Wozniak and M. Gorska-Ponikowska, Potential health benefits of olive oil and plant polyphenols, Int. J. Mol. Sci. 19 (2018) 547; https://doi.org/10.3390/ijms19030686

26. M. Celano, V. Maggisano, S. M. Lepore, D. Russo and S. Bulotta, Secoiridoids of olive and derivatives as potential coadjuvant drugs in cancer: A critical analysis of experimental studies, Pharmacol. Res. 142 (2019) 77-86; https://doi.org/10.1016/j.phrs.2019.01.045

27. J. Delgado-Lista, P. Perez-Martinez, J. F. Alcala-Diaz, A. I. Perez-Caballero, F. Gomez-Delgado, F. Fuentes, G. Quintana-Navarro, F. Lopez-Segura, A. M. Ortiz-Morales, N. Delgado-Casado, E. M. Yubero-Serrano, A. Camargo, C. Marin, F. Rodriguez-Cantalejo, P. Gomez-Luna, J. M. Ordovas, J. Lopez-Miranda and F. Perez-Jimenez, CORonary Diet Intervention with Olive oil and cardiovascular PREVention study (the CORDIOPREV study): Rationale, methods, and baseline characteristics: A clinical trial comparing the efficacy of a Mediterranean diet rich in olive oil versus a low-fat diet on cardiovascular disease in coronary patients, Am. Heart J. 177 (2016) 42-50; https:// doi.org/10.1016/j.ahj.2016.04.011

28. S. Garcia-Calzon, M. A. Martinez-Gonzalez, C. Razquin, F. Aros, J. Lapetra, J. Alfredo Martinez, G. Zalba and A. Marti, Mediterranean diet and telomere length in high cardiovascular risk subjects from the PREDIMED-NAVARRA study, Clin. Nutr. 35 (2016) 1399-1405; https://doi. org/10.1016/j.clnu.2016.03.013

29. A. Medina-Remon, R. Casas, A. Tressserra-Rimbau, E. Ros, M. A. Martinez-Gonzalez, M. Fito, D. Corella, J. Salas-Salvado, R. M. Lamuela-Raventos and R. Estruch, Polyphenol intake from a Med- 
iterranean diet decreases inflammatory biomarkers related to atherosclerosis: a substudy of the PREDIMED trial., Br. J. Clin. Pharmacol. 83 (2017) 114-128; https://doi.org/10.1111/bcp.12986

30. Commission Regulation (EU) No 432/2012 of 16 May 2012 establishing a list of permitted health claims made on foods, other than those referring to the reduction of disease risk and to children's development and health Text with EEA relevance, (n.d.) 40.

31. J. A. Menendez, A. Vazquez-Martin, R. Colomer, J. Brunet, A. Carrasco-Pancorbo, R. Garcia-Villalba, A. Fernandez-Gutierrez and A. Segura-Carretero, Olive oil's bitter principle reverses acquired autoresistance to trastuzumab (Herceptin ${ }^{\mathrm{TM}}$ ) in HER2-overexpressing breast cancer cells, BMC Cancer 7 (2007); https://doi.org/10.1186/1471-2407-7-80

32. J. Ferlay, I. Soerjomataram, R. Dikshit, S. Eser, C. Mathers, M. Rebelo, D. M. Parkin, D. Forman and F. Bray, Cancer incidence and mortality worldwide: Sources, methods and major patterns in GLOBOCAN 2012: Globocan 2012, Int. J. Cancer 136 (2015) E359-E386; https://doi.org/10.1002/ijc.29210

33. A. Ahmad Farooqi, S. Fayyaz, A. Silva, A. Sureda, S. Nabavi, A. Mocan, S. Nabavi and A. Bishayee, Oleuropein and cancer chemoprevention: The link is hot, Molecules 22 (2017) 705; https:// doi.org/10.3390/molecules22050705

34. M. A. Khanfar, S. K. Bardaweel, M. R. Akl and K. A. El Sayed, Olive oil-derived oleocanthal as potent inhibitor of mammalian target of rapamycin: Biological evaluation and molecular modeling studies: oleocanthal is a potent mTOR inhibitor, Phytother. Res. 29 (2015) 1776-1782; https://doi. org/10.1002/ptr.5434

35. J. Calahorra, E. Martínez-Lara, C. De Dios and E. Siles, Hypoxia modulates the antioxidant effect of hydroxytyrosol in MCF-7 breast cancer cells, PLOS ONE 13 (2018) e0203892; https://doi. org/10.1371/journal.pone.0203892

36. Y. Z. H.-Y. Hashim, J. Worthington, P. Allsopp, N. G. Ternan, E. M. Brown, M. J. McCann, I. R. Rowland, S. Esposto, M. Servili and C. I. R. Gill, Virgin olive oil phenolics extract inhibit invasion of HT115 human colon cancer cells in vitro and in vivo, Food Funct. 5 (2014) 1513-1519; https://doi. org/10.1039/c4fo00090k

37. H. Zubair, A. Bhardwaj, A. Ahmad, S. K. Srivastava, M. A. Khan, G. K. Patel, S. Singh and A. P. Singh, Hydroxytyrosol induces apoptosis and cell cycle arrest and suppresses multiple oncogenic signaling pathways in prostate cancer cells, Nutrit. Cancer 69 (2017) 932-942; https://doi.org /10.1080/01635581.2017.1339818

38. H. Song, D. Y. Lim, J. I. Jung, H. J. Cho, S. Y. Park, G. T. Kwon, Y.-H. Kang, K. W. Lee, M.-S. Choi and J. H. Y. Park, Dietary oleuropein inhibits tumor angiogenesis and lymphangiogenesis in the B16F10 melanoma allograft model: a mechanism for the suppression of high-fat diet-induced solid tumor growth and lymph node metastasis, Oncotarget 8 (2017) 32027-32042; https://doi. org/10.18632/oncotarget.16757

39. R. Fabiani, P. Rosignoli, A. D. Bartolomeo, R. Fuccelli, M. Servili, G. F. Montedoro and G. Morozzi, Oxidative DNA damage is prevented by extracts of olive oil, hydroxytyrosol, and other olive phenolic compounds in human blood mononuclear cells and HL60 cells, J. Nutr. 138 (2008) 14111416. https://doi.org/10.1093/jn/138.8.1411

40. I. Potočnjak, M. Škoda, E. Pernjak-Pugel, M. P. Peršić and R. Domitrović, Oral administration of oleuropein attenuates cisplatin-induced acute renal injury in mice through inhibition of ERK signaling, Mol. Nutr. Food Res. 60 (2016) 530-541; https://doi.org/10.1002/mnfr.201500409

41. I. O. Sherif and M. M. H. Al-Gayyar, Oleuropein potentiates anti-tumor activity of cisplatin against HepG2 through affecting proNGF/NGF balance, Life Sci. 198 (2018) 87-93; https://doi. org/10.1016/j.lfs.2018.02.027

42. I. O. Sherif, The effect of natural antioxidants in cyclophosphamide-induced hepatotoxicity: Role of Nrf2/HO-1 pathway, Int. Immunopharmacol. 61 (2018) 29-36; https://doi.org/10.1016/j.intimp.2018.05.007 
43. J. Ruzzolini, S. Peppicelli, E. Andreucci, F. Bianchini, A. Scardigli, A. Romani, G. la Marca, C. Nediani and L. Calorini, Oleuropein, the main polyphenol of Olea europaea leaf extract, has an anti-cancer effect on human BRAF melanoma cells and potentiates the cytotoxicity of current chemotherapies, Nutrients 10 (2018) 1950; https://doi.org/10.3390/nu10121950

44. N. El-azem, M. Pulido-Moran, C. L. Ramirez-Tortosa, J. L. Quiles, F. E. Cara, P. Sanchez-Rovira, S. Granados-Principal and Mc. Ramirez-Tortosa, Modulation by hydroxytyrosol of oxidative stress and antitumor activities of paclitaxel in breast cancer, Eur. J. Nutr. 58 (2019) 1203-1211; https://doi. org/10.1007/s00394-018-1638-9

45. A. Coccia, L. Mosca, R. Puca, G. Mangino, A. Rossi and E. Lendaro, Extra-virgin olive oil phenols block cell cycle progression and modulate chemotherapeutic toxicity in bladder cancer cells, Oncol. Rep. 36 (2016) 3095-3104; https://doi.org/10.3892/or.2016.5150

46. M. H. Elamin, A. B. Elmahi, M. H. Daghestani, E. M. Al-Olayan, R. A. Al-Ajmi, A. F. Alkhuriji, S. S. Hamed and M. F. Elkhadragy, Synergistic anti-breast-cancer effects of combined treatment with oleuropein and doxorubicin in vivo, Altern. Ther. Health Med. 25 (2019) 17-24.

47. E. Terzuoli, G. Nannelli, M. Frosini, A. Giachetti, M. Ziche and S. Donnini, Inhibition of cell cycle progression by the hydroxytyrosol-cetuximab combination yields enhanced chemotherapeutic efficacy in colon cancer cells, Oncotarget 8 (2017) 83207-83224; https://doi.org/10.18632/oncotarget.20544

48. N. M. Ayoub, A. B. Siddique, H. Y. Ebrahim, M. M. Mohyeldin and K. A. El Sayed, The olive oil phenolic (-)-oleocanthal modulates estrogen receptor expression in luminal breast cancer in vitro and in vivo and synergizes with tamoxifen treatment, Europ. J. Pharmacol. 810 (2017) 100-111; https://doi.org/10.1016/j.ejphar.2017.06.019

49. A. B. Siddique, H. Y. Ebrahim, M. R. Akl, N. M. Ayoub, A. A. Goda, M. M. Mohyeldin, S. K. Nagumalli, W. M. Hananeh, Y.-Y. Liu, S. A. Meyer and K. A. El Sayed, (-)-Oleocanthal combined with lapatinib treatment synergized against HER-2 positive breast cancer in vitro and in vivo, Nutrients 11 (2019) 412; https://doi.org/10.3390/nu11020412

50. R. Ghanbari, F. Anwar, K. M. Alkharfy, A.-H. Gilani and N. Saari, Valuable nutrients and functional bioactives in different parts of olive (Olea europaea L.) - A review, Int. J. Mol. Sci. 13 (2012) 3291-3340; https://doi.org/10.3390/ijms13033291

51. D. Boskou, Olive Oil: Chemistry and Technology, $2^{\text {nd }}$ ed., AOCS Publishing., Champaign 2006; https:// doi.org/10.1201/9781439832028

52. S. Cicerale, X. A. Conlan, A. J. Sinclair and R. S. J. Keast, Chemistry and health of olive oil phenolics, Crit. Rev. Food Sci. Nutr. 49 (2008) 218-236; https://doi.org/10.1080/10408390701856223

53. A. Bendini, L. Cerretani, A. Carrasco-Pancorbo, A. M. Gómez-Caravaca, A. Segura-Carretero, A. Fernández-Gutiérrez and G. Lercker, Phenolic molecules in virgin olive oils: A survey of their sensory properties, health effects, antioxidant activity and analytical methods. An overview of the last decade, Molecules 12 (2007) 1679-1719.

54. C. Jakobušić Brala, M. Barbarić, A. Karković Marković, S. Uršić, Biomedicinal Aspects and Activities of Olive Oil Phenolic Compounds, in Handbook of Olive Oil: Phenolic Compounds, Production and Health Benefits (Ed. J. Miloš), Nova Science Publishers, Inc., New York, 2017, pp. 47-85. ISBN: 978-1-53612357-9.

55. S. Rigacci and M. Stefani, Nutraceutical properties of olive oil polyphenols. An itinerary from cultured cells through animal models to humans, Int. J. Mol. Sci. 17 (2016) 843; https://doi. org/10.3390/ijms17060843

56. H. Shamshoum, F. Vlavcheski and E. Tsiani, Anticancer effects of oleuropein, BioFactors 43 (2017) 517-528; https://doi.org/10.1002/biof.1366 
57. M. Imran, M. Nadeem, S. A. Gilani, S. Khan, M. W. Sajid and R. M. Amir, Antitumor perspectives of oleuropein and its metabolite hydroxytyrosol: Recent updates, J. Food Sci. 83 (2018) 1781-1791; https://doi.org/10.1111/1750-3841.14198

58. A. M. Borzì, A. Biondi, F. Basile, S. Luca, E. S. D. Vicari and M. Vacante, Olive oil effects on colorectal cancer, Nutrients 11 (2019) 32; https://doi.org/10.3390/nu11010032

59. A. Di Francesco, A. Falconi, C. Di Germanio, M. V. Micioni Di Bonaventura, A. Costa, S. Caramuta, M. Del Carlo, D. Compagnone, E. Dainese, C. Cifani, M. Maccarrone and C. D'Addario, Extravirgin olive oil up-regulates CB1 tumor suppressor gene in human colon cancer cells and in rat colon via epigenetic mechanisms, J. Nutr. Biochem. 26 (2015) 250-258; https://doi.org/10.1016/j. jnutbio.2014.10.013

60. Z. K. Hassan, M. H. Elamin, M. H. Daghestani, S. A. Omer, E. M. Al-Olayan, M. A. Elobeid, P. Virk and O. B. Mohammed, Oleuropein induces anti-metastatic effects in breast cancer, Asian Pac. J. Cancer Prev. 13 (2012) 4555-4559; https://doi.org/10.7314/APJCP.2012.13.9.4555

61. C. I. R. Gill, A. Boyd, E. McDermott, M. McCann, M. Servili, R. Selvaggini, A. Taticchi, S. Esposto, G. Montedoro, H. McGlynn and I. Rowland, Potential anti-cancer effects of virgin olive oil phenolson colorectal carcinogenesis models in vitro, Int. J. Cancer 117 (2005) 1-7; https://doi.org/10.1002/ ijc. 21083

62. S. Sánchez-Fidalgo, I. Villegas, A. Cárdeno, E. Talero, M. Sánchez-Hidalgo, V. Motilva and C. Alarcón de la Lastra, Extra-virgin olive oil-enriched diet modulates DSS-colitis-associated colon carcinogenesis in mice, Clin. Nutr. 29 (2010) 663-673; https://doi.org/10.1016/j.clnu.2010.03.003

63. A. P. Femia, P. Dolara, M. Servili, S. Esposto, A. Taticchi, S. Urbani, A. Giannini, M. Salvadori and G. Caderni, No effects of olive oils with different phenolic content compared to corn oil on 1,2-dimethylhydrazine-induced colon carcinogenesis in rats, Eur. J. Nutr. 47 (2008) 329-334; https://doi. org/10.1007/s00394-008-0731-x

64. B. Pampaloni, C. Mavilia, S. Fabbri, A. Romani, F. Ieri, A. Tanini, F. Tonelli and M. L. Brandi, In vitro effects of extracts of extra virgin olive oil on human colon cancer cells, Nutr. Cancer 66 (2014) 1228-1236; https://doi.org/10.1080/01635581.2014.951727

65. A. Coccia, D. Bastianelli, L. Mosca, R. Monticolo, I. Panuccio, A. Carbone, A. Calogero and E. Lendaro, Extra virgin olive oil phenols suppress migration and invasion of T24 human bladder cancer cells through modulation of matrix metalloproteinase-2, Nutr. Cancer 66 (2014) 946-954; https://doi.org/10.1080/01635581.2014.922204

66. B. Polini, M. Digiacomo, S. Carpi, S. Bertini, F. Gado, G. Saccomanni, M. Macchia, P. Nieri, C. Manera and S. Fogli, Oleocanthal and oleacein contribute to the in vitro therapeutic potential of extra virgin oil-derived extracts in non-melanoma skin cancer, Toxicol. In Vitro 52 (2018) 243-250; https://doi.org/10.1016/j.tiv.2018.06.021

67. M.-C. López de las Hazas, C. Piñol, A. Macià and M.-J. Motilva, Hydroxytyrosol and the colonic metabolites derived from virgin olive oil intake induce cell cycle arrest and apoptosis in colon cancer cells, J. Agric. Food Chem. 65 (2017) 6467-6476; https://doi.org/10.1021/acs.jafc.6b04933

68. R. Fabiani, M. V. Sepporta, P. Rosignoli, A. De Bartolomeo, M. Crescimanno and G. Morozzi, Anti-proliferative and pro-apoptotic activities of hydroxytyrosol on different tumour cells: the role of extracellular production of hydrogen peroxide, Eur. J. Nutr. 51 (2012) 455-464; https:/doi. org/10.1007/s00394-011-0230-3

69. L. Sun, C. Luo and J. Liu, Hydroxytyrosol induces apoptosis in human colon cancer cells through ROS generation, Food Funct. 5 (2014) 1909-1914; https://doi.org/10.1039/C4FO00187G

70. P. Rosignoli, R. Fuccelli, M. V. Sepporta and R. Fabiani, In vitro chemo-preventive activities of hydroxytyrosol: The main phenolic compound present in extra-virgin olive oil, Food Funct. 7 (2016) 301-307; https://doi.org/10.1039/C5FO00932D 
71. E. Terzuoli, A. Giachetti, M. Ziche and S. Donnini, Hydroxytyrosol, a product from olive oil, reduces colon cancer growth by enhancing epidermal growth factor receptor degradation, Mol. Nutr. Food Res. 60 (2016) 519-529; https://doi.org/10.1002/mnfr.201500498

72. B. Zhao, Y. Ma, Z. Xu, J. Wang, F. Wang, D. Wang, S. Pan, Y. Wu, H. Pan, D. Xu, L. Liu and H. Jiang, Hydroxytyrosol, a natural molecule from olive oil, suppresses the growth of human hepatocellular carcinoma cells via inactivating AKT and nuclear factor-kappa B pathways, Cancer Lett. 347 (2014) 79-87; https://doi.org/10.1016/j.canlet.2014.01.028

73. S. Li, Z. Han, Y. Ma, R. Song, T. Pei, T. Zheng, J. Wang, D. Xu, X. Fang, H. Jiang and L. Liu, Hydroxytyrosol inhibits cholangiocarcinoma tumor growth: An in vivo and in vitro study, Oncol. Rep. 31 (2014) 145-152; https://doi.org/10.3892/or.2013.2853

74. R. Sirianni, A. Chimento, A. De Luca, I. Casaburi, P. Rizza, A. Onofrio, D. Iacopetta, F. Puoci, S. Andò, M. Maggiolini and V. Pezzi, Oleuropein and hydroxytyrosol inhibit MCF-7 breast cancer cell proliferation interfering with ERK1/2 activation, Mol. Nutr. Food Res. 54 (2009) 833-840; https:// doi.org/10.1002/mnfr.200900111

75. A. Chimento, I. Casaburi, C. Rosano, P. Avena, A. De Luca, C. Campana, E. Martire, M. F. Santolla, M. Maggiolini, V. Pezzi and R. Sirianni, Oleuropein and hydroxytyrosol activate GPER/ GPR30-dependent pathways leading to apoptosis of ER-negative SKBR3 breast cancer cells, Mol. Nutr. Food Res. 58 (2014) 478-489; https://doi.org/10.1002/mnfr.201300323

76. C. Goldsmith, D. Bond, H. Jankowski, J. Weidenhofer, C. Stathopoulos, P. Roach and C. Scarlett, The olive biophenols oleuropein and hydroxytyrosol selectively reduce proliferation, influence the cell cycle, and induce apoptosis in pancreatic cancer cells, Int. J. Mol. Sci. 19 (2018) 1937; https:// doi.org/10.3390/ijms19071937

77. G. Toteda, S. Lupinacci, D. Vizza, R. Bonofiglio, E. Perri, M. Bonofiglio, D. Lofaro, A. La Russa, F. Leone, P. Gigliotti, R. A. Cifarelli and A. Perri, High doses of hydroxytyrosol induce apoptosis in papillary and follicular thyroid cancer cells, J. Endocrinol. Invest. 40 (2017) 153-162; https://doi. org/10.1007/s40618-016-0537-2

78. M. Ramírez-Expósito and J. Martínez-Martos, Anti-inflammatory and antitumor effects of hydroxytyrosol but not oleuropein on experimental glioma in vivo. A putative role for the reninangiotensin system, Biomedicines 6 (2018) 11; https://doi.org/10.3390/biomedicines6010011

79. M. H. Elamin, M. H. Daghestani, S. A. Omer, M. A. Elobeid, P. Virk, E. M. Al-Olayan, Z. K. Hassan, O. B. Mohammed and A. Aboussekhra, Olive oil oleuropein has anti-breast cancer properties with higher efficiency on ER-negative cells, Food Chem. Toxicol. 53 (2013) 310-316; https://doi. org/10.1016/j.fct.2012.12.009

80. L. Liu, K. S. Ahn, M. K. Shanmugam, H. Wang, H. Shen, F. Arfuso, A. Chinnathambi, S. A. Alharbi, Y. Chang, G. Sethi and F. R. Tang, Oleuropein induces apoptosis via abrogating NF- $k B$ activation cascade in estrogen receptor-negative breast cancer cells, J. Cell. Biochem. 120 (2019) 45044513; https://doi.org/10.1002/jcb.27738

81. M. V. Sepporta, R. Fuccelli, P. Rosignoli, G. Ricci, M. Servili, G. Morozzi and R. Fabiani, Oleuropein inhibits tumour growth and metastases dissemination in ovariectomised nude mice with MCF-7 human breast tumour xenografts, J. Funct. Foods 8 (2014) 269-273; https://doi.org/10.1016/j. jff.2014.03.027

82. A. Cárdeno, M. Sánchez-Hidalgo, M. A. Rosillo and C. A. de la Lastra, Oleuropein, a Secoiridoid Derived from Olive Tree, Inhibits the proliferation of human colorectal cancer cell through downregulation of HIF-1 $\alpha$, Nutr. Cancer 65 (2013) 147-156; https://doi.org/10.1080/01635581.2013.741758

83. C.-M. Yan, E.-Q. Chai, H.-Y. Cai, G.-Y. Miao and W. Ma, Oleuropein induces apoptosis via activation of caspases and suppression of phosphatidylinositol 3-kinase/protein kinase B pathway in HepG2 human hepatoma cell line, Mol. Med. Rep. 11 (2015) 4617-4624; https://doi.org/10.3892/ mmr.2015.3266 
84. J. Yao, J. Wu, X. Yang, J. Yang, Y. Zhang and L. Du, Oleuropein induced apoptosis in HeLa cells via a mitochondrial apoptotic cascade associated with activation of the c-Jun NH2-terminal kinase, $J$. Pharmacol. Sci. 125 (2014) 300-311; https://doi.org/10.1254/jphs.14012FP

85. R. Acquaviva, C. Di Giacomo, V. Sorrenti, F. Galvano, R. Santangelo, V. Cardile, S. Gangia, N. D'orazio, N. G. Abraham and L. Vanella, Antiproliferative effect of oleuropein in prostate cell lines, Int. J. Oncol. 41 (2012) 31-38; https://doi.org/10.3892/ijo.2012.1428

86. M. Seçme, C. Eroğlu, Y. Dodurga and G. Bağcl, Investigation of anticancer mechanism of oleuropein via cell cycle and apoptotic pathways in SH-SY5Y neuroblastoma cells, Gene 585 (2016) 93-99; https://doi.org/10.1016/j.gene.2016.03.038

87. C. R. Capo, J. Z. Pedersen, M. Falconi and L. Rossi, Oleuropein shows copper complexing properties and noxious effect on cultured SH-SY5Y neuroblastoma cells depending on cell copper content, J. Trace Elem. Med. Biol. 44 (2017) 225-232; https://doi.org/10.1016/j.jtemb.2017.08.002

88. Y. Kimura and M. Sumiyoshi, Olive leaf extract and its main component oleuropein prevent chronic ultraviolet B radiation-induced skin damage and carcinogenesis in hairless mice, J. Nutr. 139 (2009) 2079-2086; https://doi.org/10.3945/jn.109.104992

89. S. Cao, X. Zhu and L. Du, P38 MAP kinase is involved in oleuropein-induced apoptosis in A549 cells by a mitochondrial apoptotic cascade, Biomed. Pharmacother. 95 (2017) 1425-1435; https://doi. org/10.1016/j.biopha.2017.09.072

90. W. Wang, J. Wu, Q. Zhang, X. Li, X. Zhu, Q. Wang, S. Cao and L. Du, Mitochondria-mediated apoptosis was induced by oleuropein in H1299 cells involving activation of p38 MAP kinase, J. Cell. Biochem. 120 (2019) 5480-5494; https://doi.org/10.1002/jcb.27827

91. L. Parkinson and R. Keast, Oleocanthal, a phenolic derived from virgin olive oil: A review of the beneficial effects on inflammatory disease, Int. J. Mol. Sci. 15 (2014) 12323-12334; https://doi. org/10.3390/ijms150712323

92. P. Khanal, W.-K. Oh, H. J. Yun, G. M. Namgoong, S.-G. Ahn, S.-M. Kwon, H.-K. Choi and H. S. Choi, p-HPEA-EDA, a phenolic compound of virgin olive oil, activates AMP-activated protein kinase to inhibit carcinogenesis, Carcinogenesis 32 (2011) 545-553; https://doi.org/10.1093/carcin/bgr001

93. M. R. Akl, N. M. Ayoub, M. M. Mohyeldin, B. A. Busnena, A. I. Foudah, Y.-Y. Liu and K. A. E. Sayed, Olive phenolics as c-Met inhibitors: (-)-Oleocanthal attenuates cell proliferation, invasiveness, and tumor growth in breast cancer models, PLoS ONE 9 (2014) e97622; https://doi.org/10.1371/journal. pone.0097622

94. A. Elnagar, P. Sylvester and K. El Sayed, (-)-Oleocanthal as a c-Met inhibitor for the control of metastatic breast and prostate cancers, Planta Med. 77 (2011) 1013-1019; https://doi.org/10.1055/s0030-1270724

95. R. Diez-Bello, I. Jardin, J. J. Lopez, M. El Haouari, J. Ortega-Vidal, J. Altarejos, G. M. Salido, S. Salido and J. A. Rosado, (-)-Oleocanthal inhibits proliferation and migration by modulating Ca2+ entry through TRPC6 in breast cancer cells, Biochim. Biophys. Acta BBA - Mol. Cell Res. 1866 (2019) 474-485; https://doi.org/10.1016/j.bbamcr.2018.10.010

96. S. Fogli, C. Arena, S. Carpi, B. Polini, S. Bertini, M. Digiacomo, F. Gado, A. Saba, G. Saccomanni, M. C. Breschi, P. Nieri, C. Manera and M. Macchia, Cytotoxic activity of oleocanthal isolated from virgin olive oil on human melanoma cells, Nutr. Cancer 68 (2016) 873-877; https://doi.org/10.1080/01 635581.2016.1180407

97. Y. Gu, J. Wang and L. Peng, (-)-Oleocanthal exerts anti-melanoma activities and inhibits STAT3 signaling pathway, Oncol. Rep. 37 (2017) 483-491; https://doi.org/10.3892/or.2016.5270

98. T. Pei, Q. Meng, J. Han, H. Sun, L. Li, R. Song, B. Sun, S. Pan, D. Liang and L. Liu, (-)-Oleocanthal inhibits growth and metastasis by blocking activation of STAT3 in human hepatocellular carcinoma, Oncotarget 7 (2016) 43475-43491; https://doi.org/10.18632/oncotarget.9782 
99. A. Cusimano, D. Balasus, A. Azzolina, G. Augello, M. R. Emma, C. Di Sano, R. Gramignoli, S. C. Strom, J. A. Mccubrey, G. Montalto and M. Cervello, Oleocanthal exerts antitumor effects on human liver and colon cancer cells through ROS generation, Int. J. Oncol. 51 (2017) 533-544; https:// doi.org/10.3892/ijo.2017.4049

100. M. Scotece, R. Gómez, J. Conde, V. Lopez, J. J. Gómez-Reino, F. Lago, A. B. Smith III and O. Gualillo, Oleocanthal inhibits proliferation and MIP-1 expression in human multiple myeloma cells, Curr. Med. Chem. 20 (2013) 2467-2475; https://doi.org/10.2174/0929867311320190006

101. J. M. Calderón-Montaño, A. Madrona, E. Burgos-Morón, M. L. Orta, S. Mateos, J. L. Espartero and M. López-Lázaro, Selective cytotoxic activity of new lipophilic hydroxytyrosol alkyl ether derivatives, J. Agric. Food Chem. 61 (2013) 5046-5053; https://doi.org/10.1021/jf400796p

102. R. Bernini, M. S. Gilardini Montani, N. Merendino, A. Romani and F. Velotti, Hydroxytyrosolderived compounds: A basis for the creation of new pharmacological agents for cancer prevention and therapy, J. Med. Chem. 58 (2015) 9089-9107; https://doi.org/10.1021/acs.jmedchem.5b00669

103. R. Bernini, I. Carastro, G. Palmini, A. Tanini, R. Zonefrati, P. Pinelli, M. L. Brandi and A. Romani, Lipophilization of hydroxytyrosol-enriched fractions from Olea europaea L. byproducts and evaluation of the in vitro effects on a model of colorectal cancer cells, J. Agric. Food Chem. 65 (2017) 6506-6512; https://doi.org/10.1021/acs.jafc.6b05457

104. S. Bulotta, R. Corradino, M. Celano, J. Maiuolo, M. D'Agostino, M. Oliverio, A. Procopio, S. Filetti and D. Russo, Antioxidant and antigrowth action of peracetylated oleuropein in thyroid cancer cells, J. Mol. Endocrinol. 51 (2013) 181-189; https://doi.org/10.1530/JME-12-0241

105. S. Bulotta, R. Corradino, M. Celano, M. D’Agostino, J. Maiuolo, M. Oliverio, A. Procopio, M. Iannone, D. Rotiroti and D. Russo, Antiproliferative and antioxidant effects on breast cancer cells of oleuropein and its semisynthetic peracetylated derivatives, Food Chem. 127 (2011) 1609-1614; https:// doi.org/10.1016/j.foodchem.2011.02.025

106. B. A. Busnena, A. I. Foudah, T. Melancon and K. A. El Sayed, Olive secoiridoids and semisynthetic bioisostere analogues for the control of metastatic breast cancer, Bioorg. Med. Chem. 21 (2013) 21172127; https://doi.org/10.1016/j.bmc.2012.12.050

107. M. M. Mohyeldin, M. R. Akl, H. Y. Ebrahim, A. M. Dragoi, S. Dykes, J. A. Cardelli and K. A. E. Sayed, The oleocanthal-based homovanillyl sinapate as a novel c-Met inhibitor, Oncotarget 7 (2016) 32247-32273; https://doi.org/10.18632/oncotarget.8681

108. B. Salehi, P. Zucca, M. Sharifi-Rad, R. Pezzani, S. Rajabi, W. N. Setzer, E. M. Varoni, M. Iriti, F. Kobarfard and J. Sharifi-Rad, Phytotherapeutics in cancer invasion and metastasis, Phytother. Res. 32 (2018) 1425-1449; https://doi.org/10.1002/ptr.6087

109. R. Fabiani, M. V. Sepporta, T. Mazza, P. Rosignoli, R. Fuccelli, A. De Bartolomeo, M. Crescimanno, A. Taticchi, S. Esposto, M. Servili and G. Morozzi, Influence of cultivar and concentration of selected phenolic constituents on the in vitro chemiopreventive potential of olive oil extracts, J. Agric. Food Chem. 59 (2011) 8167-8174; https://doi.org/10.1021/jf201459u

110. T. Kubota, S. W. Matsuzaki, Y. Hoshiya, M. Watanabe, M. Kitajima, F. Asanuma, Y. Yamada, J. Koh, Antitumor activity of paclitaxel against human breast carcinoma xenografts serially transplanted into nude mice, J. Surg. Oncol. 64 (1997) 115-121.

111. S. V. Singh, D. Scalamogna, H. Xia, S. O’Toole, D. Roy, E. O. Emerson, V. Gupta and H. A. Zaren, Biochemical characterization of a mitomycin C-resistant human bladder cancer cell line, Int. J. Cancer. 65 (1996) 852-857; https://doi.org/10.1002/(SICI)1097-0215(19960315)65:6<852::AID-IJC24>3.0.CO;2-4

112. L. Kelland, The resurgence of platinum-based cancer chemotherapy, Nat. Rev. Cancer 7 (2007) 573584; https://doi.org/10.1038/nrc2167

113. S. Cerig, F. Geyikoglu, M. Bakir, S. Colak, M. Sonmez, K. Koc, Hepatoprotective effect of oleuropein against cisplatin-induced liver damage in rat, Int. J. Med. Health Sci. 10 (2016) 264-271. 
114. F. Geyikoglu, H. Isikgoz, H. Onalan, S. Colak, S. Cerig, M. Bakir, M. Hosseinigouzdagani, K. Koc, H. S. Erol, Y. S. Saglam and S. Yildirim, Impact of high-dose oleuropein on cisplatin-induced oxidative stress, genotoxicity and pathological changes in rat stomach and lung, J. Asian Nat. Prod. Res. 19 (2017) 1214-1231; https://doi.org/10.1080/10286020.2017.1317751

115. M. Bakir, F. Geyikoglu, K. Koc and S. Cerig, Therapeutic effects of oleuropein on cisplatin-induced pancreas injury in rats, J. Can. Res. Ther. 14 (2018) 671; https://doi.org/10.4103/jcrt.JCRT_1040_16

116. G. Ventura, R. Abbattista, C. D. Calvano, C. De Ceglie, I. Losito, F. Palmisano and T. R. Cataldi, Tandem mass spectrometry characterization of a conjugate between oleuropein and hydrated cisdiammineplatinum(II), Rapid Commun. Mass Spectrom. 33 (2019) 657-666; https://doi.org/10.1002/ rcm.8394

117. P. Przychodzen, R. Wyszkowska, M. Gorzynik-Debicka, T. Kostrzewa, A. Kuban-Jankowska and M. Gorska-Ponikowska, Anticancer potential of oleuropein, the polyphenol of olive oil, with 2-methoxyestradiol, separately or in combination, in human osteosarcoma cells, Anticancer Res. 39 (2019) 1243-1251; https://doi.org/10.21873/anticanres.13234

118. U. Ernest, H.-Y. Chen, M.-J. Xu, Y. D. Taghipour, M. H. H. Bin Asad, R. Rahimi and G. Murtaza, Anti-cancerous potential of polyphenol-loaded polymeric nanotherapeutics, Molecules 23 (2018) 2787; https://doi.org/10.3390/molecules23112787

119. A. K. Jain, K. Thanki and S. Jain, Co-encapsulation of tamoxifen and quercetin in polymeric nanoparticles: Implications on oral bioavailability, antitumor efficacy, and drug-induced toxicity, Mol. Pharmaceutics 10 (2013) 3459-3474; https://doi.org/10.1021/mp400311j 